\title{
Comparison of Two Approaches for Estimating Precipitation Elasticity of Streamflow in China's Main River Basins
}

\author{
Xinyao Zhou, ${ }^{1}$ Yongqiang Zhang, ${ }^{2}$ and Yonghui Yang1 \\ ${ }^{1}$ Key Laboratory of Agricultural Water Resources, Key Laboratory of Agricultural Water Saving, \\ Center for Agricultural Resources Research, Institute of Genetics and Developmental Biology, Chinese Academy of Sciences, \\ 286 Huaizhong Road, Shijiazhuang 050021, China \\ ${ }^{2}$ CSIRO Land and Water Flagship, P.O. Box 1666, Canberra, ACT 2601, Australia
}

Correspondence should be addressed to Yonghui Yang; yonghui.yang@sjziam.ac.cn

Received 14 October 2014; Revised 5 February 2015; Accepted 8 February 2015

Academic Editor: Gwo-Fong Lin

Copyright (C) 2015 Xinyao Zhou et al. This is an open access article distributed under the Creative Commons Attribution License, which permits unrestricted use, distribution, and reproduction in any medium, provided the original work is properly cited.

Two widely used approaches, nonparametric approach and Budyko framework approach, were used to calculate precipitation elasticity of streamflow $(\varepsilon)$ in China's main river basins. While the Budyko framework illustrates only the effect of climate on $\varepsilon$, the nonparametric approach illustrates the effects of both climate and human activity on $\varepsilon$. Both approaches showed similar spatial pattern of $\varepsilon$, with high values for northern arid catchments and low values for southern humid catchments, suggesting high sensitivity of streamflow to climate in the arid catchments in China's north. Inland catchments had low $\varepsilon$ values, probably because most of the annual streamflow was driven by glacial and snowmelt. While strong anthropologic activities reduce the sensitivity of streamflow to precipitation in some northern arid catchments, which was indicated by lower $\varepsilon$ values produced by nonparametric approach, the combined use of the two approaches underscored the significance in identifying the effects of anthropologic factors on streamflow.

\section{Introduction}

As precipitation is a major factor of streamflow, it is important that water resources scientists and managers understand the sensitivity of streamflow to precipitation. Most studies involving streamflow sensitivity are based on conceptual catchment modeling by varying atmospheric inputs to estimate changes in streamflow $[1,2]$. However, conceptual model is limited by high uncertainties in the structures and parameterization $[3,4]$.

Sankarasubramanian et al. [2] developed a nonparametric model for estimating precipitation elasticity of streamflow $(\varepsilon)$, which is the proportional change in streamflow resulting from changes in precipitation. While $\varepsilon=2.0$ indicates that $1 \%$ change in precipitation results in $2 \%$ change in streamflow, higher $\varepsilon$ suggests higher streamflow sensitivity to precipitation. Several studies suggest that $\varepsilon$ is highly related to catchment climate attributes, denoted as aridity index (AI), which is the ratio of mean annual potential evapotranspiration (PET) to precipitation. Using nonparametric analysis of 219 Australian catchments for a 25-year period, Chiew [5] noted that $\varepsilon$ generally increases with increasing climate dryness (i.e., increasing AI). Zheng et al. [6] also observed a positive correlation between $\varepsilon$ and AI in a long term (1960-2000) of the headwater regions of Yellow River basin. Sankarasubramanian and Vogel [7] noted that watershed aridity index together with watershed soil water holding capacity is more related to $\varepsilon$.

A major advantage of the nonparametric method is that it provides a simple estimate of the sensitivity of streamflow to changes in long-term precipitation [5]. Its main limitation is that it neglects the effects of precipitation frequency, changes in vegetation, and feedback between the atmosphere and land surface. To deal with this limitation, algorithms considering more climatic factors were developed $[6,8,9]$. Amongst them, Budyko framework estimator (driven by AI) is widely used to quantify climate elasticity of streamflow. Studies showed a strong similarity between the nonparametric estimator and the other estimators in unregulated catchments $[5,6]$. 


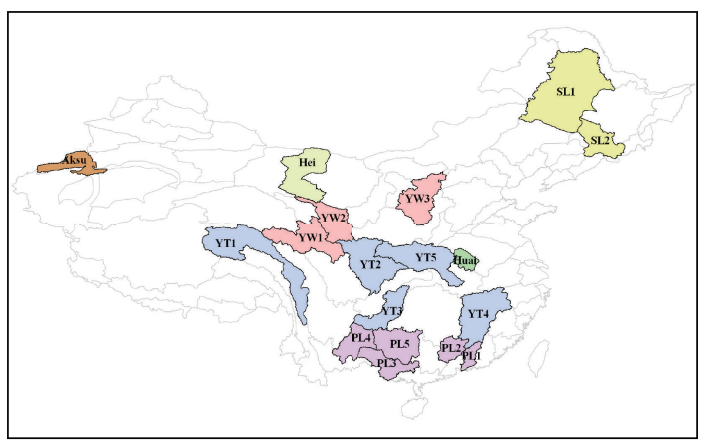

$\square$ Aksu
$\square$ Hei
$\square$ Huai
$\square$ Songliao

FIGURE 1: Location of 18 investigated catchments including 5 subcatchments in the Yangtze River basin (YT1, YT2, YT3, YT4, and YT5), 5 subcatchments in the Pearl River Basin (PL1, PL2, PL3, PL4, and PL5), 1 subcatchment in the Huai River Basin, 3 subcatchments in the Yellow River Basin (YW1, YW2, and YW3), 2 subcatchments in Songliao Basin (SL1 and SL2), Aksu River Basin, and Hei River Basin (Hei).

China stretches across various climatic regions, ranging from humid tropical climate in the south to arid/frigid temperate climate in the north and from the plains in the east to the "earth's third pole" mountains of the Tibetan Plateau in the west. Thus the water resources in the south of China are rich while those in the north are poor. The increasing water shortage in North China is driven by the rapid expansion of population, agriculture, and industry. Despite this, the response of streamflow to climate regimes and anthropogenic activities in China's main catchments remains largely unclear.

This study compares precipitation elasticity of streamflow from the nonparametric estimator with that from the Budyko framework estimator for seven main river basins in ChinaYangtze, Pearl, Yellow, Songliao, Huai, Aksu, and Hei (Figure 1). The specific objectives of this study are to (1) investigate the spatial patterns of $\varepsilon$ in the seven main river basins; (2) determine any (in)consistency between the two approaches and the related causes; and (3) compare $\varepsilon$ between catchments in China and catchments in other regions. This is critical for water scientists and managers in taking informed decisions for sustainable and environmentally friendly water resources management and for the benefits it brings to water users and society at large.

\section{Materials and Methods}

2.1. Study Area. A total of 18 of catchments with 55 years (1955-2009) of annual streamflow data were used to analyze precipitation elasticity of streamflow. The catchments belong to seven large basins (Songliao, Yellow, Huai, Yangtze, Pearl, Aksu, and Hei) stretching across different climatic zones in China. The catchment boundaries were derived from "Data Sharing Infrastructure of Earth System Science" at
TABLE 1: Surface coefficients used to convert pan evapotranspiration into potential evapotranspiration in the six investigated main basins in China.

\begin{tabular}{lcc}
\hline Basin & Coefficient & Reference \\
\hline Yangtze & 0.69 & Wang et al., 2007 [20] \\
Pearl & 0.65 & Liu et al., 2012 [21] \\
Yellow & 0.53 & Liu et al., 2004 [22] \\
Songliao & 0.62 & Liu et al., 2004 [22] \\
Huai & 0.55 & Liu et al., 2004 [22] \\
Inland (Hei and Aksu) & 0.64 & Liu et al., 2004 [22] \\
\hline
\end{tabular}

http://www.geodata.cn/Portal/metadata/viewMetadata.jsp? id=210008-10081.

Songliao basin is chilly subhumid, Yellow basin is temperate with subhumid upstream and subarid downstream, Huai basin is warm subhumid, Yangtze basin is warm with subhumid upstream and humid downstream, Pearl basin is hot humid, and Aksu and Hei basins are arid temperate. Figure 1 shows the distribution of the 18 catchments, with each catchment denoted by a unique acronym. Except for Hei, Huai, and Aksu, two letters are used to symbolize the catchments as SL for Songliao, YW for Yellow, YT for Yangtze, and PL for Pearl.

2.2. Data Types and Sources. Annual streamflow data for the catchments were obtained from China river sediment Bulletin (2000-2009) and other sources with catchment outlet hydrological station data $[10,11]$. Annual precipitation and pan evapotranspiration data from meteorological stations in the catchments were downloaded from China Meteorological Data Sharing Service System at http://cdc.cma.gov.cn/home.do. The pan evapotranspiration was measured using $20 \mathrm{~cm}$ diameter and $10 \mathrm{~cm}$ high metal pan installed at $70 \mathrm{~cm}$ above the land surface [12]. A surface coefficient factor (Table 1) was used to convert the pan evapotranspiration into PET. Simple arithmetic averages of the station-based annual precipitation and PET within the catchments were used to derive catchment-average values. And AI (aridity index) is derived from the ratio of mean annual potential evapotranspiration (PET) to precipitation.

2.3. Elasticity Estimation. Two approaches, nonparametric estimator and Budyko framework estimator, were used to calculate precipitation elasticity of streamflow. The nonparametric estimator can be expressed as [2]

$$
\varepsilon_{P}=\operatorname{median}\left(\frac{\left(Q_{i}-\bar{Q}\right) \bar{P}}{\left(P_{i}-\bar{P}\right) \bar{Q}}\right) \text {, }
$$

where $\varepsilon_{P}$ is precipitation elasticity of streamflow in a catchment; $\bar{P}$ and $\bar{Q}$ are mean annual precipitation and streamflow for the period of study; and $P_{i}$ and $Q_{i}$ are annual precipitation and streamflow for the $i$ th year. Observed annual streamflow used in calculating $\varepsilon_{P}$ reflects the impacts of natural factors and anthropogenic activities since the catchments are heavily regulated via processes such as water diversions or 
TABLE 2: Details of the six commonly used forms of Budyko framework estimator and the related derivatives.

\begin{tabular}{|c|c|c|}
\hline Function & $f(\mathrm{AI})$ & $f^{\prime}(\mathrm{AI})$ \\
\hline $\begin{array}{l}\text { Schreiber, } \\
1904[23]\end{array}$ & $1-e^{-\mathrm{AI}}$ & $e^{-\mathrm{AI}}$ \\
\hline $\begin{array}{l}\text { Ol'dekop, } \\
1911[24]\end{array}$ & $\mathrm{AI} \tanh (1 / \mathrm{AI})$ & $\tanh (1 / \mathrm{AI})-4 /\left\lfloor\operatorname{AI}\left(e^{-1 / \mathrm{AI}}+e^{1 / \mathrm{AI}}\right)^{2}\right\rfloor$ \\
\hline $\begin{array}{l}\text { Budyko, } \\
1958[25]\end{array}$ & $\mathrm{AI} \tanh (1 / \mathrm{AI})\left(1-e^{-\mathrm{AI}}\right)^{0.5}$ & $0.5\left[\mathrm{AI} \tanh (1 / \mathrm{AI})\left(1-e^{-\mathrm{AI}}\right)\right]^{-0.5}\left[\tanh (1 / \mathrm{AI})-1 / \mathrm{AIsech}^{2}(1 / \mathrm{AI})\left(1-e^{-\mathrm{AI}}\right)+\mathrm{AI} \tanh (1 / \mathrm{AI}) e^{-\mathrm{AI}}\right]$ \\
\hline $\begin{array}{l}\text { Pike, } 1964 \\
\text { [26] }\end{array}$ & $1 / \sqrt{1+\mathrm{AI}^{-2}}$ & $1 /\left[\mathrm{AI}^{3}\left(1+(1 / \mathrm{AI})^{2}\right)^{1.5}\right]$ \\
\hline $\begin{array}{l}\text { Fu, } 1981 \\
{[27]}\end{array}$ & $1+\mathrm{AI}-\left(1+\mathrm{AI}^{\alpha}\right)^{1 / \alpha}, \alpha=2.5$ & $1-\left(1+\mathrm{AI}^{2.5}\right)^{-0.6} \mathrm{AI}^{1.5}$ \\
\hline $\begin{array}{l}\text { Zhang et } \\
\text { al., 2001 } \\
{[28]}\end{array}$ & $\begin{array}{l}(1+w \mathrm{AI}) /(1+w \mathrm{AI}+1 / \mathrm{AI}) \\
w=1\end{array}$ & $\left(2 / \mathrm{AI}+1 / \mathrm{AI}^{2}\right) /(1+\mathrm{AI}+1 / \mathrm{AI})^{2}$ \\
\hline
\end{tabular}

control dams. Therefore $\varepsilon_{P}$ calculated using the nonparametric method is the combined effects of both climatic and anthropologic factors.

The second approach is the Budyko framework estimator, expressed as [9]

$$
\varepsilon_{P}=1+\frac{\mathrm{AI} f^{\prime}(\mathrm{AI})}{1-f^{\prime}(\mathrm{AI})}
$$

where $f^{\prime}(\mathrm{AI})$ is the Budyko equation derivative which is a function of AI, where AI $=\overline{\mathrm{PET}} / \bar{P}$. Here, long-term $(>5$ years) mean annual streamflow is the difference between mean annual precipitation and actual evapotranspiration (AET) in unregulated catchment $(\bar{Q}=\bar{P}-\bar{E})$. In the Budyko framework, AET is a function of AI. Thus the elasticity of the Budyko framework represents only natural or climatic effect on streamflow. Table 2 shows the six commonly used Budyko frameworks and the related derivatives. In the table, elasticity is the average of the six estimators from the six Budyko frameworks.

2.4. Cluster Analyses. Using hierarchical cluster analysis based on Euclidean distance (the shortest distance method) and at a maximum of 3 clusters, precipitation elasticity of streamflow was grouped into three clusters. Analysis in MATLAB showed that elasticity within each group (cluster) was much closer than between the different groups (clusters). This was used to determine the similarity between every two catchments in terms of the sensitivity of streamflow to precipitation.

\section{Results and Discussions}

3.1. Nonparametric and Budyko Framework Approaches. Figure 2 plotted precipitation elasticity of streamflow estimated for the 18 catchments using the nonparametric and Budyko framework approaches. Although some of the catchments such as the subcatchments of the Yangtze (YT1) and Yellow (YW2 and YW3) River basins showed large deviations, the spatial distributions of streamflow elasticity were similar for most of the investigated catchments. Elasticity for relatively arid basins (e.g., Songliao and Yellow River basins) was higher than that for relatively humid basins (e.g., Yangtze and Pearl River basins) and was lowest for inland basins. Compared with Budyko framework (hereafter denoted as PE2), estimated elasticity by nonparametric approach (hereafter denoted as PE1) was much lower for catchments with large deviations.

The large deviations in estimated elasticity between the two approaches in three catchments (YW2, YW3, and YT1) could largely result from the difference in $\varepsilon$ calculation. While nonparametric approach relies on actual streamflow and precipitation for calculation of $\varepsilon$, Budyko framework approaches, on the other hand, use purely climate variables for estimating $\varepsilon$. Thus, the comparison of the two approaches becomes very meaningful in identifying the intensity of anthropologic activities.

Catchment YW2 is in the upstream region of Yellow River basin, receiving inflows from two tributaries-Huang River and Tao River. Due to intense agricultural activities, water use in Huang River is over 50\% of the total streamflow [13]. Moreover, water-diversion projects take some $20 \%$ of flow in Datong River (the main tributary of Huang River) and deliver it to Qinwangchuan River in another province [14].

Catchment YW3 is the middle reach of Yellow River basin, receiving flows from 17 tributaries. The section of the Loess Plateau in the middle reach of Yellow River basin produces large volumes of sediments, the major driver of flooding in the downstream regions of the river. This calls for more water/soil conservation efforts such as reservoir construction and loss sediment control in the region [15]. There are some 2184 reservoirs in this section of the river [16]. Such large amount of reservoirs heavily regulates the streamflow in the middle reach and results in low streamflow sensitivity to precipitation.

Catchment YT1 is the upstream region of Jinsha River, an upstream tributary of Yangtze River. Previous studies showed that precipitation in the headwater regions of the three rivers greatly influences change in streamflow in the upstream region of Jinsha River [10]. The weak correlation between streamflow and precipitation in YT1 was because the average precipitation was only for the local catchments. 

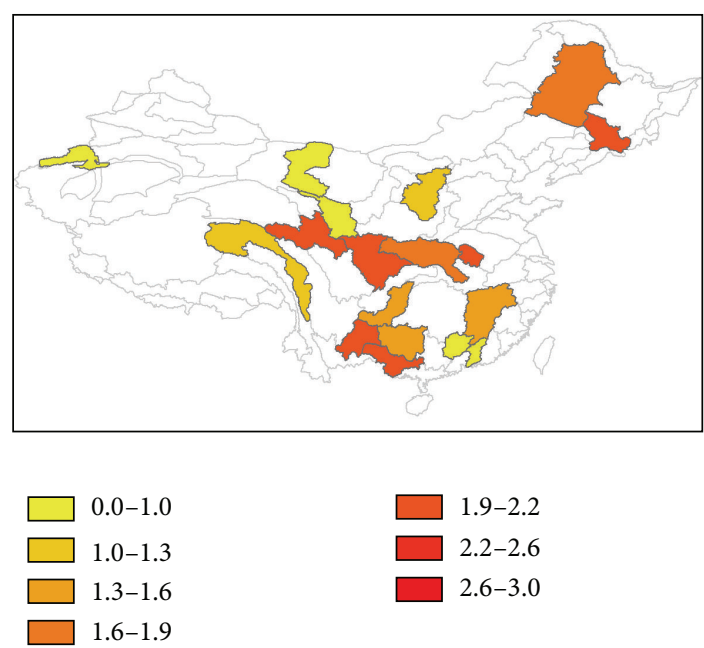

(a)
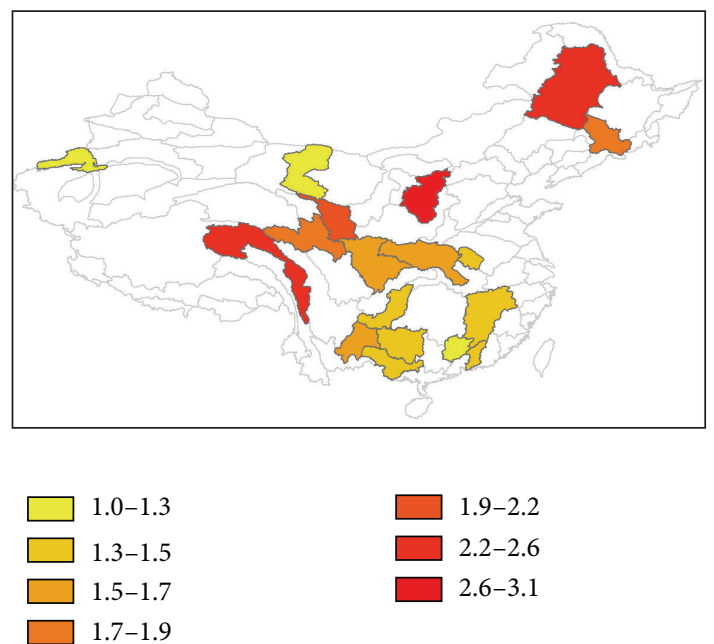

$1.0-1.3$

$1.3-1.5$

$1.7-1.9$
$1.9-2.2$

$2.2-2.6$

$2.6-3.1$

(b)

FIGURE 2: Comparison of precipitation elasticity of streamflow between nonparametric approach (a) and Budyko framework approach (b).

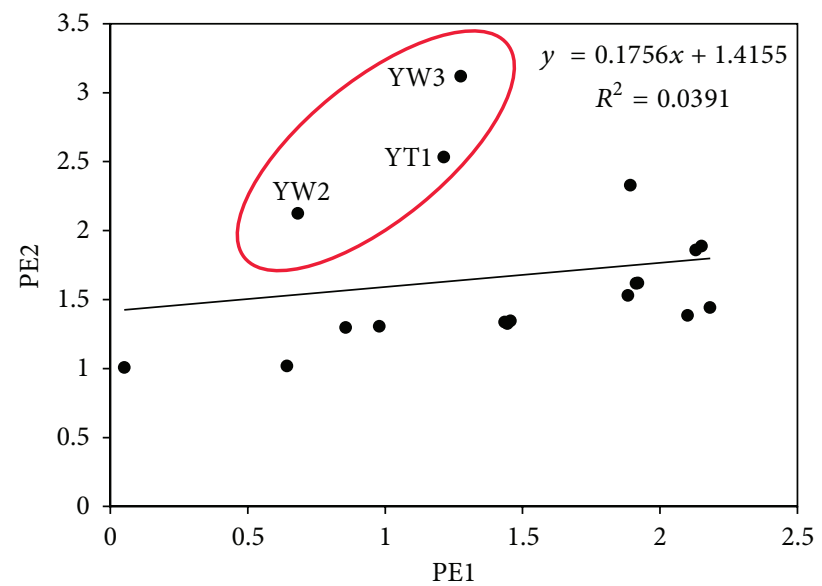

(a)

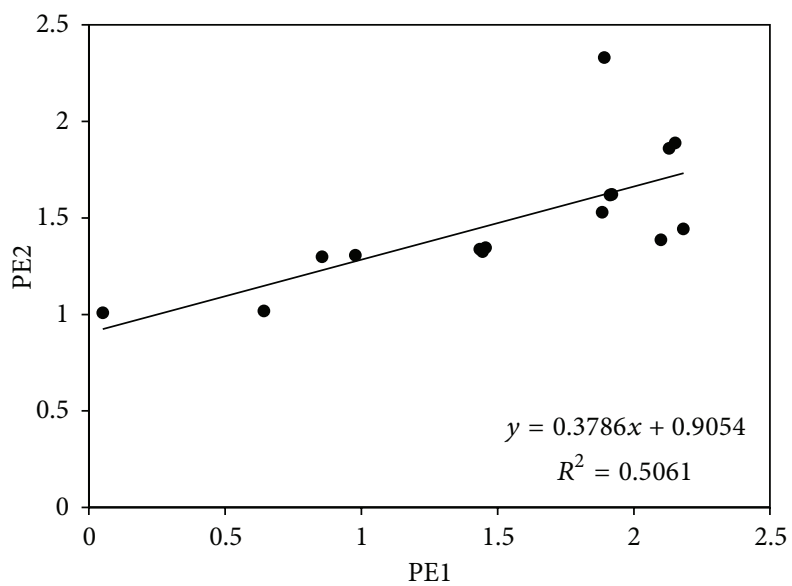

(b)

FIGURE 3: Comparison of precipitation elasticity of streamflow between nonparametric approach (PE1) with Budyko framework approach (PE2). The plot on the left is for all the catchments and the one on the right excludes three catchments in the red circle in the left plate.

There was virtually no correlation between PE1 and PE2 (Figure 3), probably due to the large deviations for YW2, YW3, and YT1 catchments. After removing these three catchments, the coefficient of determination improved to 0.5 . Because PE1 includes the combined effects of anthropogenic and climatic factors, the attribution analysis was limited to this approach.

\subsection{Nonparametric Estimated Elasticity. Figure 4 showed} how PE1 corresponds with AI, with that for the two inland catchments depicted in the inset plot of the figure. Interestingly, PE1 increased with increasing AI for humid catchments $(\mathrm{AI}<1.5)$ while it largely decreased with increasing AI for arid catchments $(\mathrm{AI}>1.5)$. It was assumed that PE1 for arid catchments differed from that for humid catchments. However, hierarchical cluster analysis showed strong similarity in arid and humid catchments in terms of streamflow sensitivity to precipitation.
Compared with natural conditions, the study suggested that streamflow in arid catchments was lower and less sensitive to precipitation. This was attributed to intensive water use due mainly to rapid expansion in population, industry, and agriculture in the country. For instance, there is intensive surface water and groundwater use in Yellow River basin (YW1, YW2, and YW3) and Songliao River basin (SL1 and SL2), limiting streamflow and worsening water shortage in the basins. The generally limited water resources in the arid north of China are not conducive for the rapidly expanding population, industry, and agriculture.

PE1 was lowest for Hei and Aksu inland catchments, probably due to low sensitivity of flow to precipitation in the catchments. According to Wang et al. [17], precipitation counts for $55 \%$, groundwater $35 \%$, and snowmelt $10 \%$ of streamflow in Hei catchment. This study suggested limited annual streamflow variation in Hei catchment, driven largely by groundwater and snowmelt. Like in Hei catchment, 
TABLE 3: Comparison of estimated elasticity in the literature with estimated elasticity in this study by the nonparametric approach.

\begin{tabular}{|c|c|c|c|c|}
\hline Catchment & Country & Period & Elasticity & Reference \\
\hline $\mathrm{MDB}$ & Australia & $1950-2006$ & 2.14 & Fu et al., 2011 [29] \\
\hline Spokane & USA & $1940-2000$ & $1.38-1.65$ & Fu et al., 2011 [29] \\
\hline Yellow River & China & $1960-2000$ & 1.76 & Fu et al., 2011 [29] \\
\hline 1337 catchments & USA & 1951-1988 & $1.5-2.5$ & Sankarasubramanian and Vogel, 2003 [7] \\
\hline 219 catchments & Australia & $25-93$ years & $2.0-3.5$ & Chiew, $2006[5]$ \\
\hline 521 catchments & Globe & $23-64$ years & $0.4-3.1$ & Chiew et al., 2006 [19] \\
\hline Yellow River (headwater) & China & $1960-2000$ & 2.1 & Zheng et al., 2009 [6] \\
\hline Han River & Korea & 1973-2006 & $1.5-2.0$ & Kim et al., 2013 [30] \\
\hline Nakdong River & Korea & 1973-2006 & $0.7-1.5$ & Kim et al., 2013 [30] \\
\hline Geum River & Korea & 1973-2006 & $1.0-2.0$ & Kim et al., 2013 [30] \\
\hline Seomjin River & Korea & 1973-2006 & $1.2-1.5$ & Kim et al., 2013 [30] \\
\hline Yeongsan River & Korea & 1973-2006 & $1.6-1.7$ & Kim et al., 2013 [30] \\
\hline Yangtze River & China & 1955-2009 & $1.2-1.9$ & This study \\
\hline Yellow River & China & 1955-2009 & $0.7-2.1$ & This study \\
\hline Pearl River & China & 1955-2009 & $0.8-2.1$ & This study \\
\hline Huai River & China & $1955-2009$ & 2.2 & This study \\
\hline Songliao & China & 1955-2009 & $1.9-2.2$ & This study \\
\hline Hei River & China & 1955-2009 & 0.6 & This study \\
\hline Aksu & China & 1955-2009 & 0.05 & This study \\
\hline
\end{tabular}

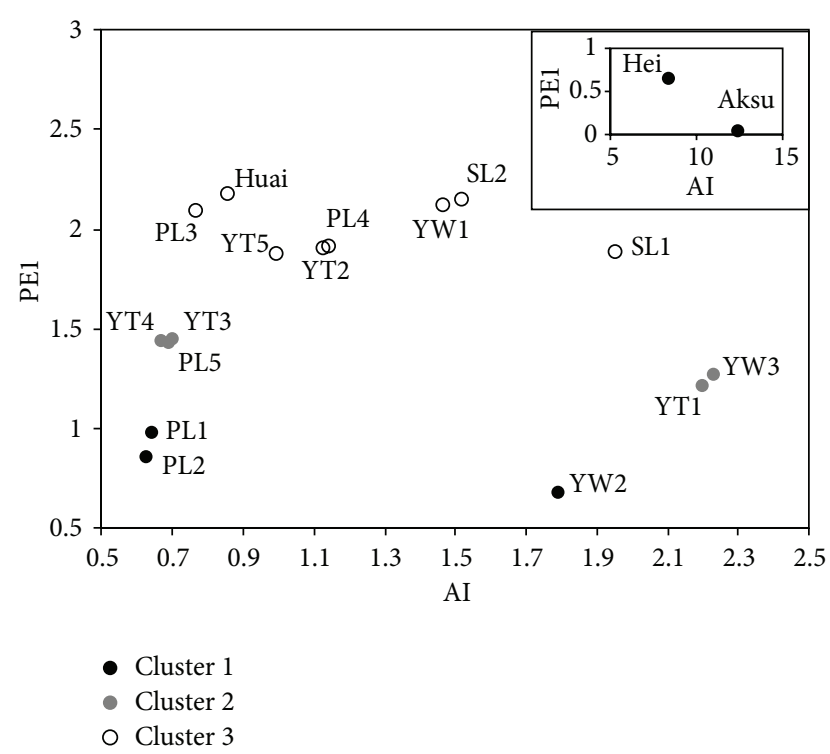

FIGURE 4: Correspondence of elasticity estimated by nonparametric approach (PE1) with aridity index. The hierarchical cluster analysis yielded three derivatives of precipitation streamflow elasticitycluster 1 denoted by shaded black circle, cluster 2 denoted by shaded grey circle, and cluster 3 denoted by unshaded circle. The inset plate is the precipitation elasticity of streamflow for Hei and Aksu inland catchments in China.

snowmelt in Aksu catchment accounts for over $40 \%$ of the total streamflow [18]. Figure 5 further clarifies this point, depicting a weak correlation between precipitation and streamflow in both Hei and Aksu catchments.
Boxplots showed the variations (by way of 7 basins) in PE1, precipitation, streamflow, and PET for the 18 catchments (Figure 6). While there was large PE1 for Yellow River basin, the variations in meteorological factors and streamflow were small. This further explained the wide discrepancies in the intensity of anthropologic activities in the basin. While variations in meteorological factors and streamflow were high in Yangtze River basin, those in PE1 were minimal. This suggested that water resources in Yangtze River basin were generally sufficient for anthropologic needs. Variations in all the estimated variables were relatively minimal for Pearl River basin, also suggesting rich water resources conditions in the basin. The lower precipitation, higher PET, and similar PE1 for Songliao River basin suggested stronger anthropologic activities in that basin than in Huai River basin. The lowest PE1 was for the two inland catchments-Songliao and Huai River basins.

3.3. Elasticity for China and Other Countries. Using the nonparametric precipitation elasticity of streamflow, the hydroclimatic characteristics of the main catchments in the world were summarized in Table 3 . The comparison in Table 3 further deepens our understanding of the characteristics of the hydrologic cycle, precipitation elasticity of streamflow, and water available in the world's major catchments.

For 1337 catchments in USA, $\varepsilon$ range is 1.5-2.5 [7] and that for 219 catchments in Australia is 2.0-3.5 [5]. Also $\varepsilon$ is notably higher for arid than for humid catchments. The global range of $\varepsilon$ is estimated at $0.4-3.1$, with high values for southeastern Australia and southern/western Africa and low values for mid-/high-latitude Northern Hemisphere [19]. 


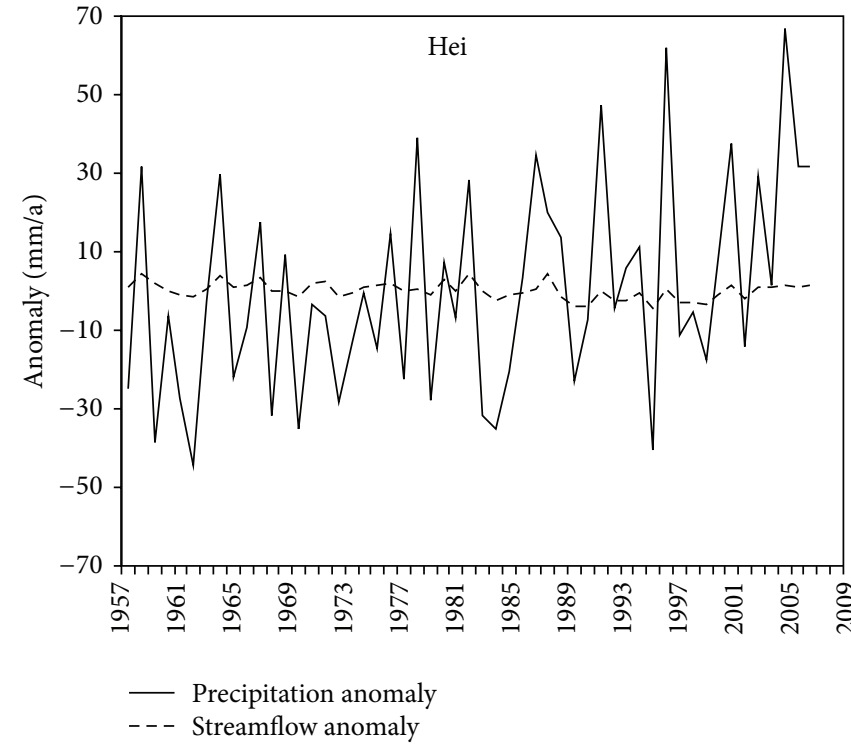

(a)

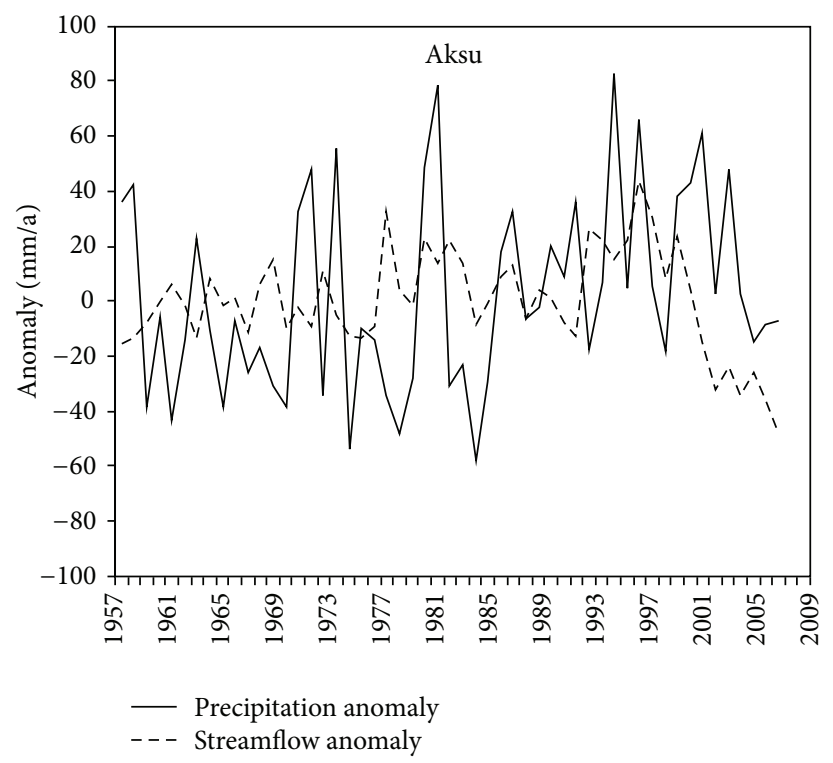

(b)

FIgURE 5: Precipitation and streamflow anomalies (1957-2009) for Hei and Aksu inland catchments in China.

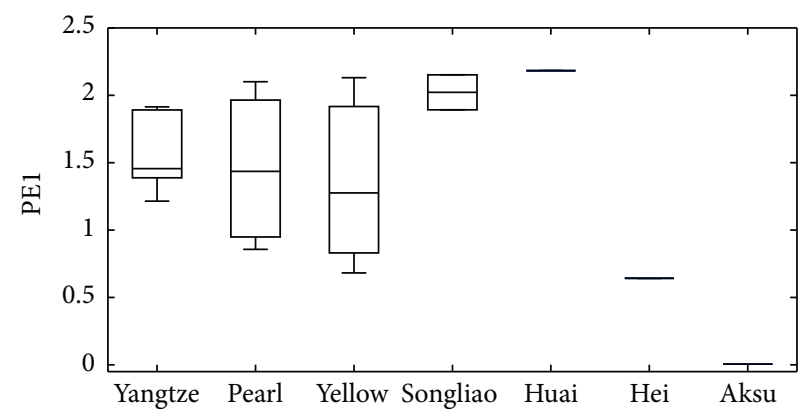

(a)

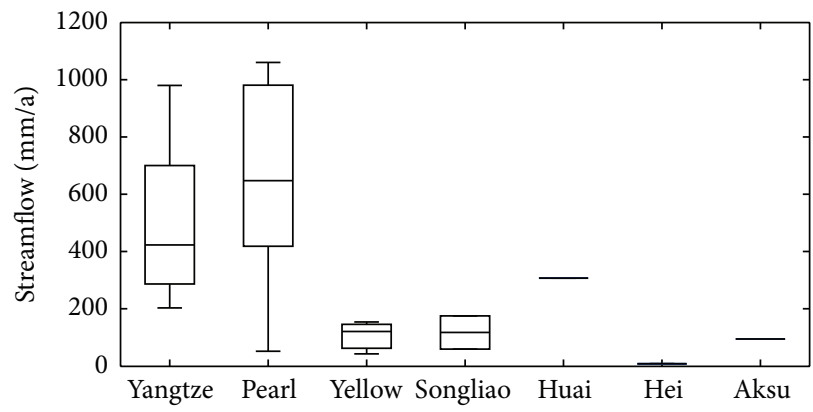

(c)

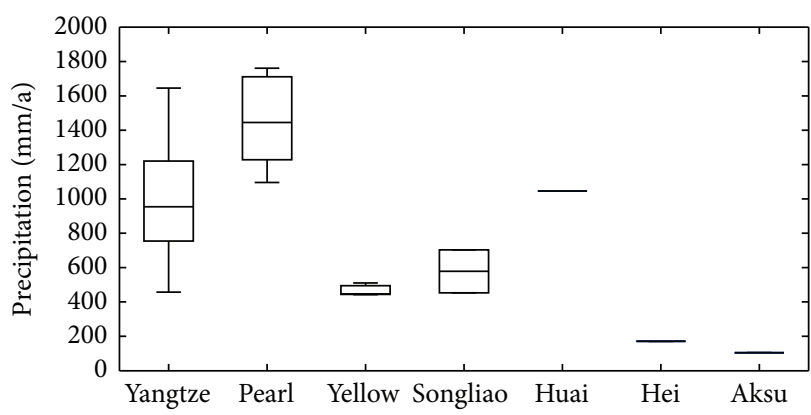

(b)

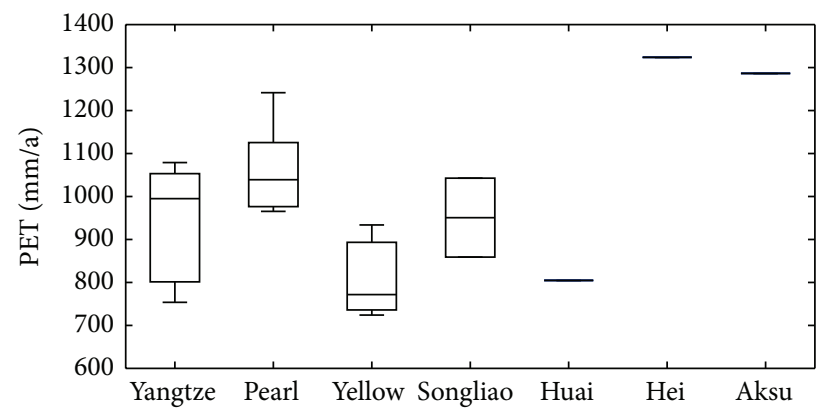

(d)

FIGURE 6: Boxplots of elasticity estimated by the nonparametric approach (PE1) for precipitation, streamflow, and potential evapotranspiration (PET) for seven main basins in China. 


\section{Conclusions}

This study used two different approaches (nonparametric and Budyko framework) to estimate precipitation elasticity of streamflow in seven main basins in China. Both the two approaches were driven by long-term (1955-2009) meteorological and streamflow data from 18 large catchments in China.

The results showed that the two approaches were generally consistent, both showing higher elasticity for dry than for wet catchments. The disparities between the two approaches were explained as the differences in the effects of anthropologic activities on streamflow in the investigated catchments. While the nonparametric estimator was positively correlated with AI for wet catchments (AI $<1.5)$, it was negatively correlated with AI for wet catchments (AI > 1.5). There were large variations in elasticity for Yellow River catchments along with minimal variations in meteorological and streamflow characteristics, suggesting varying intensities of anthropologic activities.

The study suggested that the Budyko-framework was particularly good for quantifying the effects of natural factors on precipitation elasticity of streamflow. Then the nonparametric approach was particularly fit for quantifying the effects of both anthropologic and natural factors on precipitation elasticity of streamflow. Generally, the discrepancies between the two approaches identified the effects of anthropologic activities on precipitation elasticity of streamflow. Compared with precipitation elasticity of streamflow in catchments in similar latitude zones, rivers in China were less sensitive to precipitation due to heavy anthropologic activities.

\section{Conflict of Interests}

The authors declare that there is no conflict of interests regarding the publication of this paper.

\section{References}

[1] G. H. Leavesley, "Modeling the effects of climate change on water resources-a review," Climatic Change, vol. 28, no. 1-2, pp. 159-177, 1994.

[2] A. Sankarasubramanian, R. M. Vogel, and J. F. Limbrunner, "Climate elasticity of streamflow in the United States," Water Resources Research, vol. 37, no. 6, pp. 1771-1781, 2001.

[3] L. L. Nash and P. H. Gleick, "Sensitivity of streamflow in the Colorado Basin to climatic changes," Journal of Hydrology, vol. 125, no. 3-4, pp. 221-241, 1991.

[4] J. C. Schaake, "From climate to flow," in Climate Change and U.S. Water Resources, P. E. Waggoner, Ed., chapter 8, pp. 177206, John Wiley \& Sons, New York, NY, USA, 1990.

[5] F. H. S. Chiew, "Estimation of rainfall elasticity of streamflow in Australia," Hydrological Sciences Journal, vol. 51, no. 4, pp. 613$625,2006$.

[6] H. Zheng, L. Zhang, R. Zhu, C. Liu, Y. Sato, and Y. Fukushima, "Responses of streamflow to climate and land surface change in the headwaters of the Yellow River Basin," Water Resources Research, vol. 45, no. 7, Article ID W00A19, 2009.
[7] A. Sankarasubramanian and R. M. Vogel, "Hydroclimatology of the continental United States," Geophysical Research Letters, vol. 30, no. 7, article 1363, 2003.

[8] G. Fu, S. P. Charles, and F. H. S. Chiew, "A two-parameter climate elasticity of streamflow index to assess climate change effects on annual streamflow," Water Resources Research, vol. 43, no. 11, Article ID W11419, 2007.

[9] H. Li, Y. Zhang, J. Vaze, and B. Wang, "Separating effects of vegetation change and climate variability using hydrological modelling and sensitivity-based approaches," Journal of Hydrology, vol. 420-421, pp. 403-418, 2012.

[10] Q. Zhang, C.-Y. Xu, S. Becker, and T. Jiang, "Sediment and runoff changes in the Yangtze River basin during past 50 years," Journal of Hydrology, vol. 331, no. 3-4, pp. 511-523, 2006.

[11] G. Zhao, X. Mu, A. Strehmel, and P. Tian, "Temporal variation of streamflow, sediment load and their relationship in the Yellow River Basin, China," PLoS ONE, vol. 9, no. 3, Article ID e91048, 2014.

[12] Y. Zhang, C. Liu, Y. Tang, and Y. Yang, "Trends in pan evaporation and reference and actual evapotranspiration across the Tibetan Plateau," Journal of Geophysical Research D: Atmospheres, vol. 112, no. 12, Article ID D12110, 2007.

[13] L. Bing, Q. Shao, and J. Liu, "Runoff characteristics in flood and dry seasons based on wavelet analysis in the source regions of the Yangtze and Yellow rivers," Journal of Geographical Sciences, vol. 22, no. 2, pp. 261-272, 2012.

[14] S. Zhang, D. Hua, X. Meng, and Y. Zhang, "Climate change and its driving effect on the runoff in the 'Three-River Headwaters' region," Journal of Geographical Sciences, vol. 21, no. 6, pp. 963978, 2011.

[15] Z.-B. Xin and X.-X. Yu, "Impact of vegetation restoration on hydrological processes in the middle reaches of the Yellow River, China," Forestry Studies in China, vol. 11, no. 4, pp. 209-218, 2009.

[16] The Ministry of Water Resources of the People's Republic of China, China Water Statistical Yearbook: Completed Reservoirs by Grade-I Water Resources Regions, The Ministry of Water Resources of the People's Republic of China, Beijing, China, 1989.

[17] J. Wang, H. Li, and X. Hao, "Responses of snowmelt runoff to climatic change in an inland river basin, Northwestern China, over the past 50 years," Hydrology and Earth System Sciences, vol. 14, no. 10, pp. 1979-1987, 2010.

[18] X. Gao, B. S. Ye, S. Q. Zhang, C. J. Qiao, and X. W. Zhang, "Glacier runoff variation and its influence on river runoff during 1961-2006 in the Tarim River Basin, China," Science China Earth Sciences, vol. 53, no. 6, pp. 880-891, 2010.

[19] F. H. S. Chiew, M. C. Peel, T. A. Mcmahon, and L. W. Siriwardena, "Precipitation elasticity of streamflow in catchments across the world," in Climate Variability and ChangeHydrological Impacts, Publication Number 308, pp. 256-262, International Association of Hydrological Sciences, IAHS Press, Wallingford, UK, 2006.

[20] Y. Wang, T. Jiang, O. Bothe, and K. Fraedrich, "Changes of pan evaporation and reference evapotranspiration in the Yangtze River basin," Theoretical and Applied Climatology, vol. 90, no. 1-2, pp. 13-23, 2007.

[21] C. Liu, D. Zhang, X. Liu, and C. Zhao, "Spatial and temporal change in the potential evapotranspiration sensitivity to meteorological factors in China (1960-2007)," Journal of Geographical Sciences, vol. 22, no. 1, pp. 3-14, 2012. 
[22] B. Liu, M. Xu, M. Henderson, and W. Gong, "A spatial analysis of pan evaporation trends in China, 1955-2000," Journal of Geophysical Research D: Atmospheres, vol. 109, no. 15, Article ID D15102, 2004.

[23] P. Schreiber, "Über die Beziehungen zwischen dem Niederschlag und der Wasserführung der Flüße in Mitteleuropa," Zeitschrift für Meteorologie, vol. 21, no. 10, pp. 441-452, 1904.

[24] E. M. Ol'dekop, "On evaporation from the surface of river basins," Transactions on Meteorological Observations, vol. 4, 1911.

[25] M. I. Budyko, The Heat Balance of the Earth's Surface, U.S. Department of Commerce, Washington, DC, USA, 1958, Translated from Russian by N. A. Stepanova.

[26] J. G. Pike, "The estimation of annual run-off from meteorological data in a tropical climate," Journal of Hydrology, vol. 2, no. 2, pp. 116-123, 1964.

[27] B. P. Fu, "On the calculation of the evaporation from land surface," Scientia Meteorologica Sinica, vol. 5, pp. 23-31, 1981 (Chinese).

[28] L. Zhang, W. R. Dawes, and G. R. Walker, "Response of mean annual evapotranspiration to vegetation changes at catchment scale," Water Resources Research, vol. 37, no. 3, pp. 701-708, 2001.

[29] G. Fu, F. H. S. Chiew, S. P. Charles, and F. Mpelasoka, "Assessing precipitation elasticity of streamflow based on the strength of the precipitation-streamflow relationship," in Proceedings of the 19th International Congress on Modelling and Simulation, pp. 3567-3572, Perth, Australia, December 2011.

[30] B. S. Kim, S. J. Hong, and H. D. Lee, "The potential effects of climate change on streamfow in rivers basin of korea using rainfall elasticity," Environmental Engineering Research, vol. 18, no. 1, pp. 9-20, 2013. 

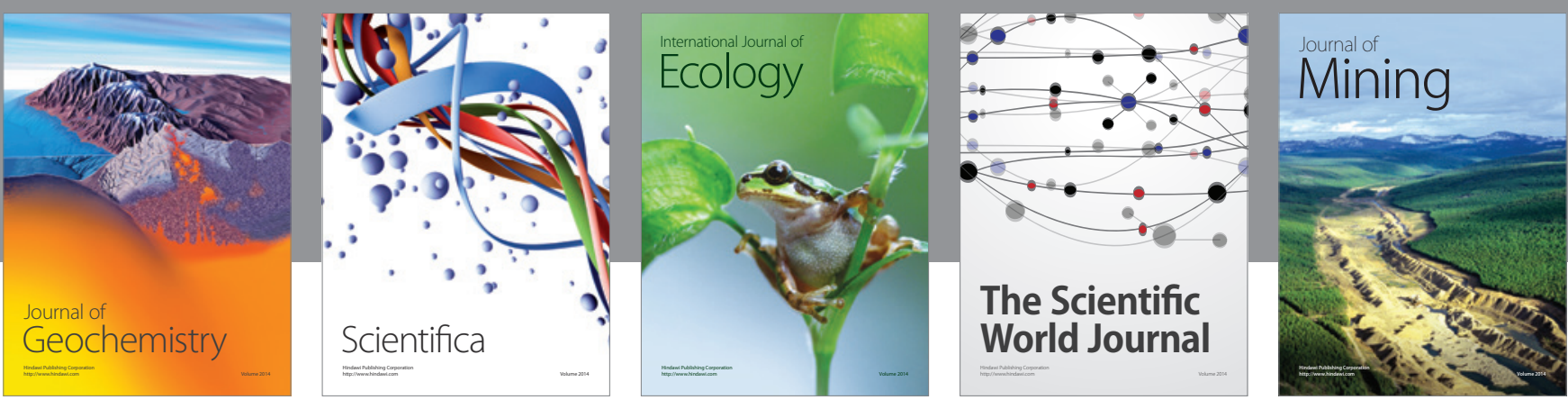

The Scientific World Journal
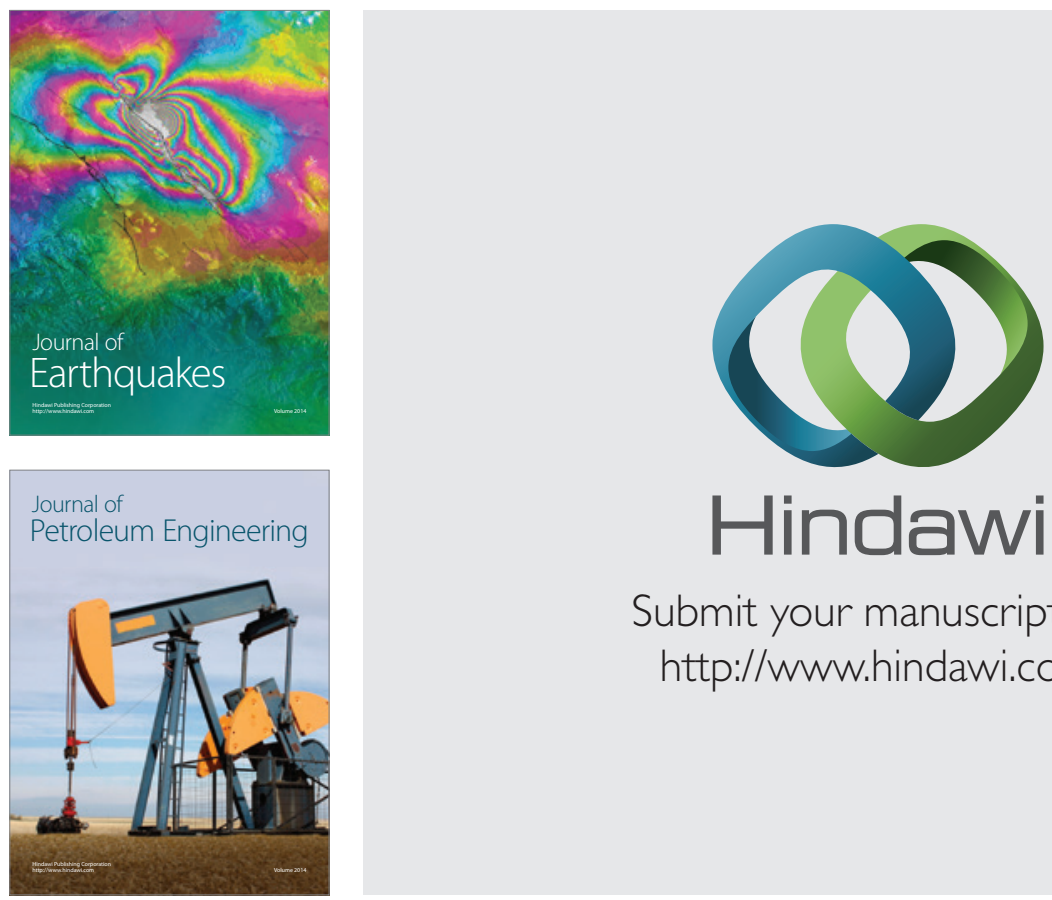

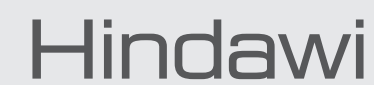

Submit your manuscripts at

http://www.hindawi.com
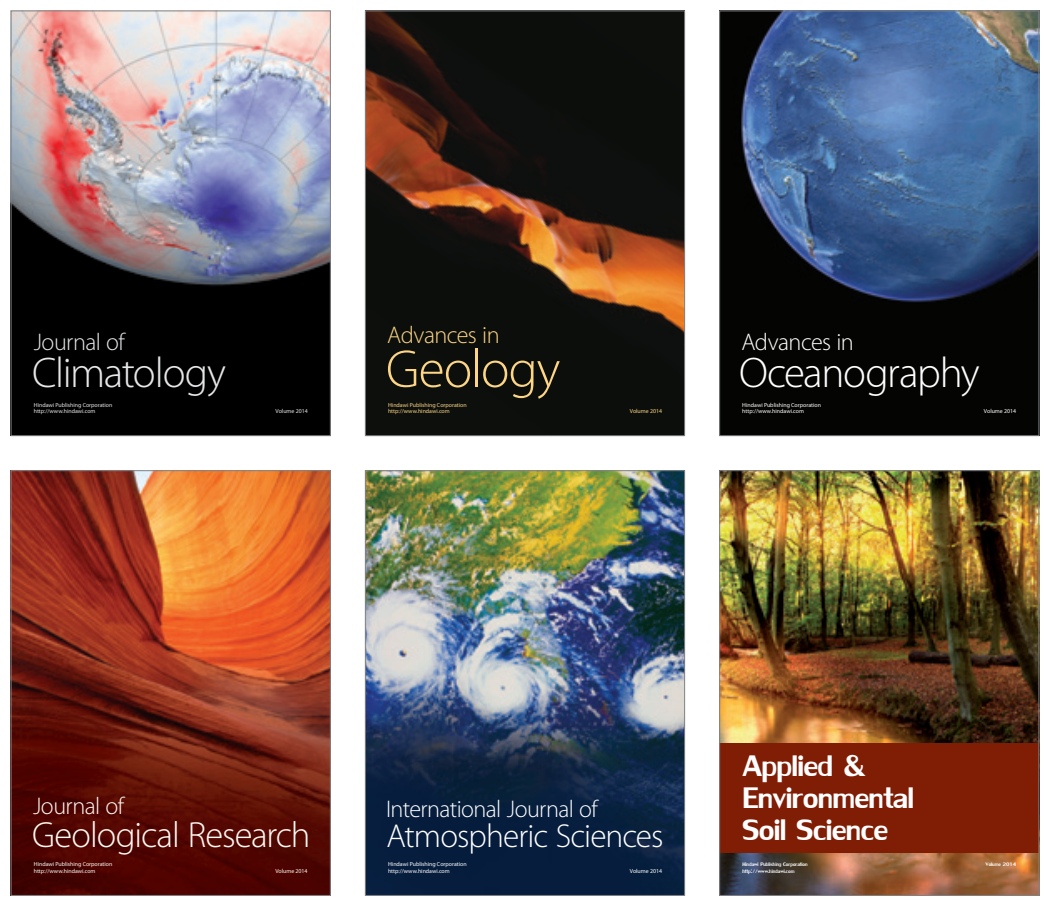
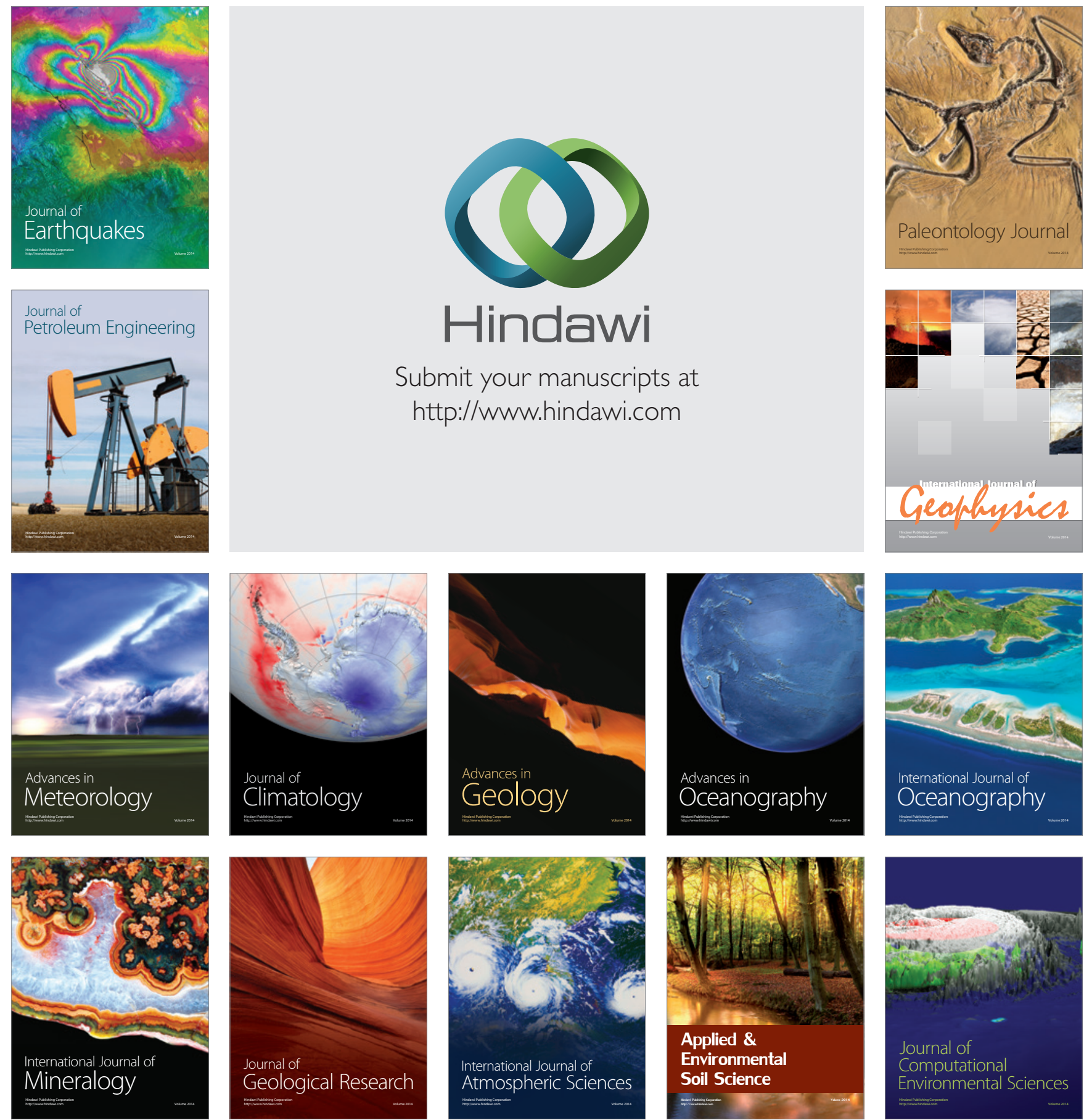